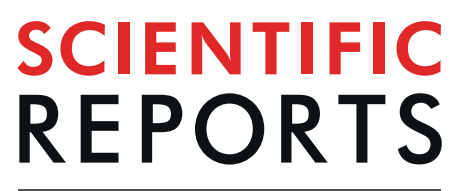

natureresearch

\title{
OPEN A C-terminal Pfs48/45 malaria transmission-blocking vaccine candidate produced in the baculovirus expression system
}

Shwu-Maan Lee $\mathbb{1}^{1 *}$, John M. Hickey ${ }^{2}$, Kazutoyo Miura ${ }^{3}$, Sangeeta B. Joshi², David B. Volkin ${ }^{2}$, C. Richter King ${ }^{1} \&$ Jordan L. Plieskatt ${ }^{1}$

The Plasmodium falciparum gametocyte surface protein, $\mathrm{Pfs} 48 / 45$, is a potential target for malaria transmission-blocking vaccines. However, due to its size and complexity, expression of the fulllength protein has been difficult, leading to focus on the C-terminal six cysteine domain (6C) with the use of fusion proteins to facilitate expression and folding. In this study, we utilized the baculovirus system to evaluate the expression of three Pfs48/45 proteins including the full-length protein, the $6 \mathrm{C}$ domain fragment and the $6 \mathrm{C}$ domain mutant to prevent glycosylation. Expression of the recombinant Pfs48/45 proteins was conducted in super Sf9 cells combined with the use of tunicamycin to prevent $N$ glycosylation. The proteins were then evaluated as immunogens in mice to demonstrate the induction of functionally active polyclonal antibody responses as measured in the standard membrane feeding assay (SMFA). Only the $6 \mathrm{C}$ protein was found to exhibit significant transmission-reducing activity. Further characterization of the biologically active $6 \mathrm{C}$ protein demonstrated it was homogeneous in terms of size, charge, conformation, absence of glycosylation, and containing proper disulfide bond pairings. This study presents an alternative expression system, without the need of a fusion protein partner, for the $\mathrm{Pfs} 48 / 456 \mathrm{C}$ protein fragment including further evaluation as a potential transmissionblocking vaccine candidate.

Malaria transmission-blocking vaccines (TBVs) are being evaluated for their potential to serve as a supplemental tool to accelerate the elimination of malaria. TBVs function via the induction of antibodies that block the fertilization or the penetration of the mosquito midgut by sexual stage parasite, thereby breaking the cycle of parasite transmission between human and mosquito hosts ${ }^{1-3}$. Several sexual stage antigens (e.g., Pfs 25 , Pfs 230 and Pfs48/45) have been identified as promising TBV targets for research or early stage clinical development. In clinical testing, Pfs25, when delivered as nanoparticles ${ }^{4}$, induced functional antibodies. However, the responses were of low magnitude and short-lived ${ }^{5,6}$. In recent years, development attention has shifted to the TBV candidates Pfs 230 and Pfs48/45 in view of the poor outcomes associated with Pfs25-based constructs and the fact that sera from Plasmodium infected individuals are associated with transmission-blocking antibodies attributable to these gametocyte surface antigens ${ }^{7}$. Moreover, affinity purified anti-Pfs $48 / 45$ and anti-Pfs 230 antibodies from naturally exposed individuals can prevent the transmission of cultured $P$. falciparum gametocytes ${ }^{8}$, when concentrated nine times the physiological concentration, thereby demonstrating the functionality of these natural antibody responses and the potential for these antigens in TBV development.

While the preclinical ${ }^{9-11}$ and clinical (NCT 02942277) development of Pfs230 is in progress, the development of Pfs $48 / 45$ as a TBV candidate has remained challenging. The Pfs $48 / 45$ protein, expressed on the surface of gametocyte, serves an essential role in the male gamete fertility ${ }^{12}$ and belongs to the same cysteine-rich structural family as Pfs $230^{13}$. Consisting of 448 amino acids in its full-length form, the native Pfs48/45 sequence also contains a signal sequence, three cysteine motifs organized as one and half double domains, a putative glycosylphosphatidylinositol anchor and seven potential $N$-glycosylation sites ${ }^{14}$.

${ }^{1}$ PATH's Malaria Vaccine Initiative (MVI), 455 Massachusetts Avenue NW, Suite 1000, Washington, DC, 20001-2621, USA. ${ }^{2}$ Department of Pharmaceutical Chemistry, Vaccine Analytics and Formulation Center, University of Kansas, Lawrence, KS, 66047, USA. '3aboratory of Malaria and Vector Research, National Institute of Allergy and Infectious Diseases, National Institutes of Health, Rockville, MD, 20852, USA. *email: smlee@path.org 
The expression of soluble and properly folded full-length Pfs $48 / 45$ has presented a challenge for recombinant expression systems, thus leading to focused efforts on expression of individual domains of Pfs $48 / 45$. This difficulty in expression has largely been attributed to its three-domain structure and large number of disulfide bonds (16 cysteines arranged as eight disulfide pairs). Conformational monoclonal antibodies are available and have facilitated the design and characterization of recombinant Pfs $48 / 45$ proteins. For example, rat monoclonal antibody 85RF45.1, developed by Roeffen et al. using the native gametocyte antigen, recognizes the C-terminal epitope $\mathrm{I}^{15}$ and possesses potent transmission-blocking activities (TBA) with an $\mathrm{IC}_{80}$ of $1-3 \mu \mathrm{g} / \mathrm{mL}$ as measured in the SMFA ${ }^{16}$. To design a recombinant TBV, Outchkourov et al. analyzed the transmission-blocking (TB) epitopes on the Pfs $48 / 45$ protein and determined the C-terminal six-cysteine module termed $6 \mathrm{C}$ was recognized by the $85 \mathrm{RF} 45.1$ monoclonal antibody ${ }^{17}$. An extended design including the middle four-cysteine module and the C-terminal 6C, designated as 10C, has also been attempted. When the 10C protein was fused with maltose binding protein and expressed in the E.coli periplasmic space ${ }^{18}$, the resulting protein was functionally active in mice, however, the overall yield ( $1 \mathrm{mg} / \mathrm{L}$ culture) was too low for vaccine development.

Numerous expression systems have since been explored to produce a Pfs $48 / 45$ protein, however, the reported yields and purity of properly folded protein have not been satisfactory for the resulting protein to be considered a vaccine candidate ${ }^{19}$. Bacterial expression systems have generally been preferred, given their ability to produce a non-glycosylated protein, but have also been challenging given the complex structural nature of Pfs $48 / 45$. Singh et al. reported successful expression and characterization of $6 \mathrm{C}$ as a chimera fused with $\mathrm{N}$-terminal region of GLURP (R0) and a C-terminal his tag in the Lactococcus lactis system ${ }^{20}$. Biochemical characterization has also been well reported for R0.6C, with a final purified yield of $25 \mathrm{mg} / \mathrm{L}$ culture as well as the ability to elicit functional antibodies in rats ${ }^{20}$. While this approach is promising, we sought to generate Pfs $48 / 45$ antigens that might focus the immune response onto the $6 \mathrm{C}$ region alone without fusion partners.

Expression in eukaryotic systems has also been reported and attempted for Pfs $48 / 45$ based antigens. Such systems add additional complexity since Plasmodium parasites lack $N$-linked glycosylation machinery ${ }^{21}$ but Pfs $48 / 45$ contains seven potential $\mathrm{N}$-glycosylation sites when expressed in eukaryotic systems. Thus, the protein could be aberrantly glycosylated impacting the ability to generate functional antibodies. Evidence suggested by Kapula et al. that expression in human embryonic kidney (HEK) 293 cells of unmodified Pfs $48 / 45(48 / 45+\mathrm{Ngln})$ and modified Pfs $48 / 45$ that removes glycosylation sites (48/45-NGln) could be achieved ${ }^{22}$. Unfortunately, the resulting recombinant protein contained high molecular weight aggregates, with modified (-NGln) demonstrating no significant TBA. This work demonstrated the importance of the primary sequence integrity for this protein. Mamedov et al. co-expressed Pfs48/45 with Endoglycosidase H (Endo H) in the plant based expression system and the recombinant deglycosylated Pfs $48 / 45$ generated functional antibodies in mice ${ }^{23}$. This work demonstrated the feasibility of recombinant expression of full-length Pfs $48 / 45$ protein.

Recently, Kundu et al. expressed 6C in HEK cells for the study of its binding to 85RF45.1 ${ }^{16}$ and Lennartz et al. expressed full-length Pfs48/45, 10C and 6C fragments in the Drosophila S2 expression system ${ }^{24}$. The full-length Pfs $48 / 45$ was used to raise a panel of mouse monoclonal antibodies and the fragments utilized to map the binding regions of those resulting antibodies ${ }^{24}$. These studies show that it is feasible to express $6 \mathrm{C}$ without a fusion partner.

In this study, we explore the use of an alternative expression system to generate recombinant Pfs $48 / 45$ proteins. Previously, we demonstrated the baculovirus system could be used to produce properly folded Pfs 25 and an $\mathrm{N}$-terminal fragment of Pfs 230 at reasonable yields with high purity, and more importantly, with functional activity $^{9,10,25-27}$. In view of this success, we tested whether full-length Pfs $48 / 45$, the $6 \mathrm{C}$ domain protein and the 6C mutant can be produced using this system, and whether the expressed proteins retained native conformation to elicit TBA. We report here the biochemical and immunological characterization of the expressed proteins, and the results suggest that the $6 \mathrm{C}$ fragment may be feasible from a vaccine development perspective given further optimization. Moreover, the well characterized and homogeneous $6 \mathrm{C}$ fragment may also have utility as a reference reagent to support malaria vaccine development.

\section{Results}

Baculovirus produces full-length Pfs48/45 and 6C fragments. The design of baculovirus expression constructs was based on previous work on the Pfs $230 \mathrm{C} 1$ recombinant protein ${ }^{9}$. A signal peptide (MKFLVNVALVFMVVYISYIYAD) to facilitate secretion through ER pathway, and a six histidine C-terminal tag were included to facilitate protein expression and purification of the full-length Pfs48/45 (aa 28-427), 6C fragment (aa 291-427) and 6C Mutant (aa 291-427 with N299Q and N303D mutations). In this report, these three recombinant proteins are designated Pfs48/45-FL, 6C and 6C-Mut, respectively, as derived from baculovirus expression. The insect cells used in the baculovirus system have active glycosylation machinery while the evidence to date is that $P$. falciparum parasites do not ${ }^{21}$. To address the glycosylation propensity of the Pfs $48 / 45$ molecule during insect cell production, two approaches were undertaken. In an effort to minimize modifications (e.g., mutations) to the native gene sequence, the primary approach was to include tunicamycin, an antibiotic, in the expression culture as it has been demonstrated to effectively inhibit $N$-glycosylation in the insect/baculovirus expression system ${ }^{28,29}$. The secondary approach to eliminate $N$-glycosylation in the $6 \mathrm{C}$ fragment was to mutate the two high probability $\mathrm{N}$-glycosylation sites at positions N299 and N303 in the 6C construct (termed 6C-Mut).

To test the initial feasibility of expression in the presence of tunicamycin, $30 \mathrm{~mL}$ culture was infected with baculovirus at 1 MOI (multiplicity of infection) and tunicamycin was added to a final concentration of $0,0.2 \mathrm{or} 1 \mu \mathrm{g} /$ $\mathrm{mL}$. It should be noted, as shown in Supplementary Table S1, that tunicamycin significantly inhibited cell growth, and this inhibition may have impacted protein expression overall. The recombinant proteins were not expressed in the supernatant but were rather located in cell pellets as indicated by SDS-PAGE and anti-his Western (Fig. 1). All three proteins were expressed at the expected molecular weight (Fig. 1a). However, the Pfs48/45-FL and 6C protein both presented as double bands (Fig. 1b) in the presence of 0 or $0.2 \mu \mathrm{g} / \mathrm{mL}$ tunicamycin, likely the result of glycosylation. At tunicamycin concentrations of $1 \mu \mathrm{g} / \mathrm{mL}$, the glycosylation appeared completely inhibited as 
a

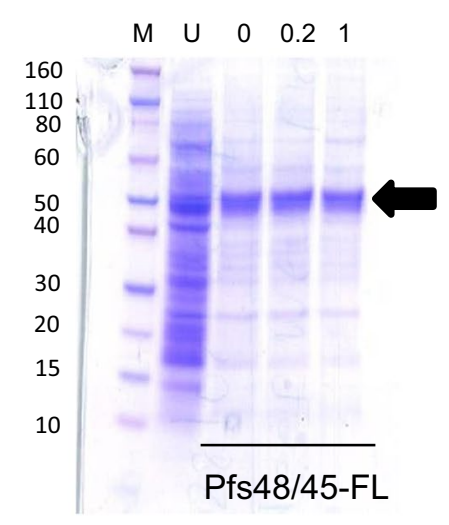

b

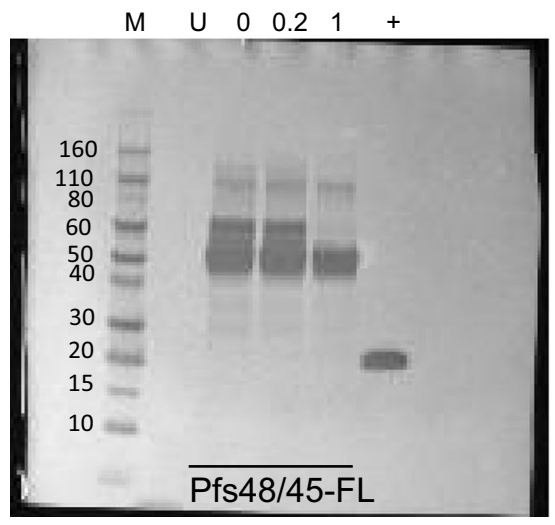

$\begin{array}{llllll}M & \mathrm{U} & 0 & 0.2 & 1 & 0\end{array}$

0.21
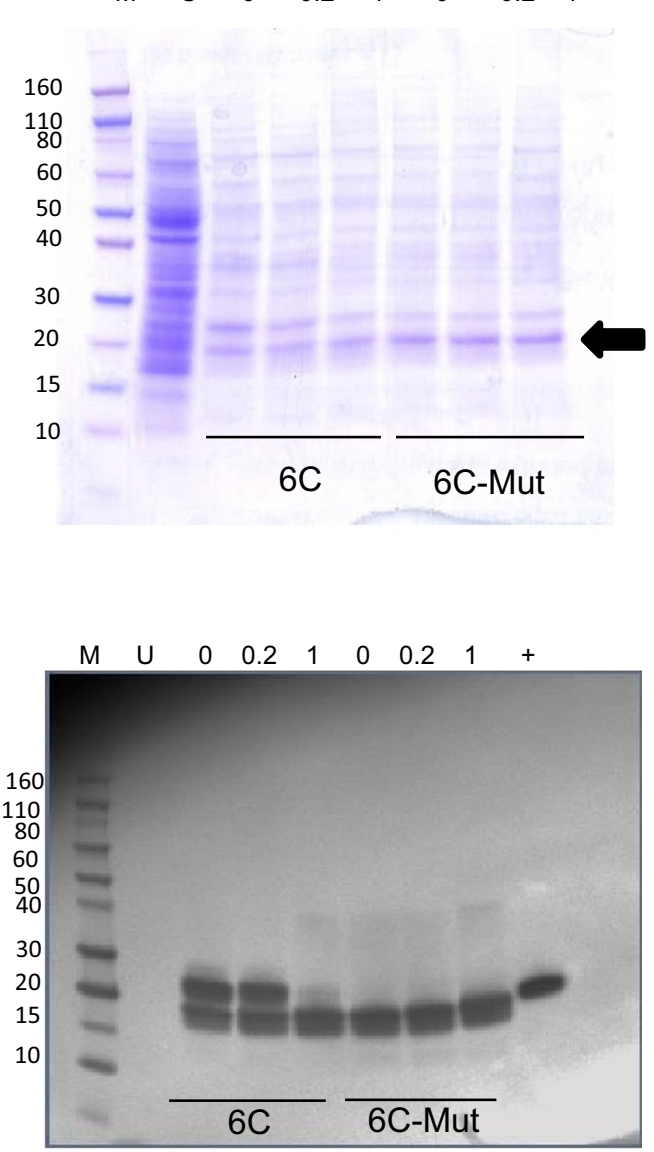

Figure 1. SDS-PAGE and Western blot analysis of Pfs $48 / 45$ baculovirus/insect cell pellets. Insect cell pellets from 96 hours expression with Pfs48/45-FL, 6C and 6C-Mut were evaluated by (a) Two separate Coomassie stained gels and (b) Two separate Western blots with anti-His antibody. M: Marker (kDa); U: Uninfected control at 96 hours (pellet); 0, 0.2, 1: Tunicamycin concentrations in $\mu \mathrm{g} / \mathrm{mL} ;+$ : Irrelevant his-tag protein positive control. Gels and Western blots were run at the same time and in similar manner. SDS-PAGE gels stained with Coomassie (a) were cropped to areas of interest (Left panel to first five lanes) at time of image acquisition. Images were not further manipulated.

the proteins presented as a single band (Fig. 1b). Tunicamycin did not impact the banding pattern of 6C-Mut (Fig. 1b), which presented as a single band under all conditions, as $\mathrm{N}$-glycosylation was already likely inhibited through the mutation of the two high probability $N$-glycosylation sites.

To produce sufficient recombinant protein for further characterization and in vivo evaluation, the insect culture was scaled up to $10 \mathrm{~L}$, and $1 \mu \mathrm{g} / \mathrm{mL}$ tunicamycin was selected for addition during infection, based on the results of small-scale experiments. The proteins were successfully extracted from homogenized cell pellets in the presence of $2 \%$ sarkosyl and purified by IMAC (immobilized metal affinity column) and size-exclusion chromatography into a formulation buffer of $20 \mathrm{mM}$ HEPES, $150 \mathrm{mM} \mathrm{NaCl}, 0.2 \%$ Tween $80, \mathrm{pH} 7.5$. The initial process, as presented here yielded $<3 \mathrm{mg}$ of purified protein per liter of culture for $6 \mathrm{C}$ and $6 \mathrm{C}$-Mut. These yields were considered low, but sufficient to conduct initial evaluations. The Pfs48/45-FL was produced in even smaller quantities $(<0.1 \mathrm{mg} / \mathrm{L}$ culture). Due to the much higher yield of the $6 \mathrm{C}$ fragment, we now prefer this as a candidate antigen, however, production of the full-length was sufficient to be used as a comparator in subsequent in vivo studies. Efforts to improve expression were not explored further in the study reported here, and yield optimization would be required for further development as a TBV antigen. This however remains plausible given our past experience in process optimization ${ }^{10}$, and with new focus on maximizing yield from the cell pellet, knowing that a homogeneous properly disulfide-paired protein can result.

The 6C and 6C-Mut proteins were $>90 \%$ pure by SDS-PAGE and densitometry and Pfs $48 / 45$-FL was $>80 \%$ pure (Fig. 2a). To determine whether the important epitope I was preserved, the proteins were also analyzed via Western blot with the 85RF45.1 monoclonal antibody (Fig. 2b). Native Pfs48/45, present in NF54 parasite extract as well as the recombinant Pfs48/45-FL and 6C proteins were successfully recognized by this reduction sensitive monoclonal, indicating this functional epitope was preserved. However, the 6C-Mut protein was not recognized (Fig. 2b) by 85RF45.1, likely indicating that the mutation of two $N$-glycosylation sites disrupted epitope I conformation. 
a

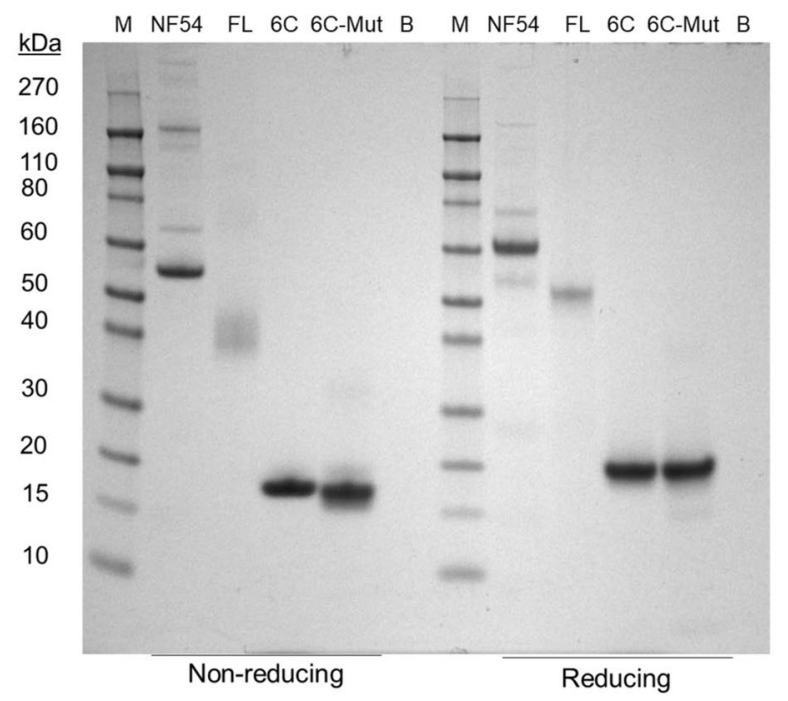

b

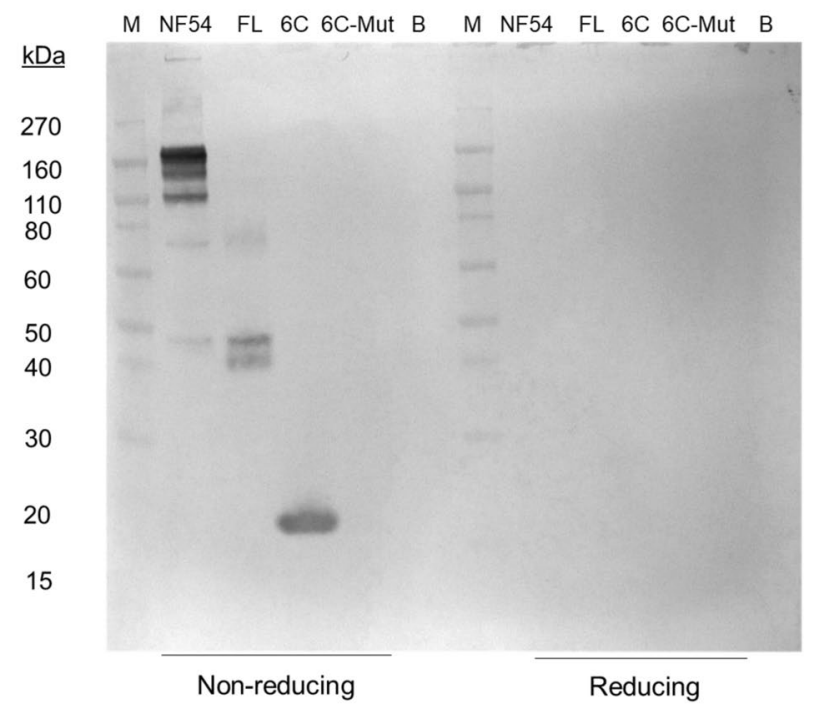

Figure 2. SDS-PAGE and Western blot analysis of purified Pfs $48 / 45$ recombinant proteins. Purified proteins were analyzed via SDS-PAGE followed by (a) Coomassie staining and (b) Western blot with a functional monoclonal antibody (85RF45.1). Lanes loaded under non-reducing and reducing conditions (M) Marker; (B) Blank; (NF54) NF54 parasite extract as positive control; (FL) Pfs48/45-FL; 6C and 6C-Mut proteins as labeled. Both (a: Coomassie stained and b: transfer for Western blot) were loaded in an identical manner and run at the same time. Images were cropped to areas of interest (Gel or membrane edges) at time of image acquisition. Images were not further manipulated.

Baculovirus expressed $6 \mathrm{C}$ fragment elicits functional antibodies. To test if the recombinant proteins represented the native conformation and therefore could elicit functional antibodies, a mouse immunogenicity study was conducted on all three baculovirus Pfs $48 / 45$ proteins formulated with the water-in-oil emulsion adjuvant Montanide ISA720. Antibody responses against each immunogen were determined by ELISA, and all recombinant proteins were immunogenic with median ELISA titer of $>4,000$ units and negative controls showing undetectable level of response ( $<18$ ELISA units) against all three proteins. Biological activity of induced antibodies was then evaluated by SMFA using purified IgG derived from serum pool from all mice in each immunization group. In the initial assay (Fig. 3a and Supplementary Table S2, Feed \#1), all purified IgGs (one pooled sample per group of 10 mice) were tested at $750 \mu \mathrm{g} / \mathrm{mL}$. The IgGs from $6 \mathrm{C}(3 \mu \mathrm{g})$ and $6 \mathrm{C}(10 \mu \mathrm{g})$ groups were associated with significant reductions in oocyst density ( $>98 \%$ reduction, $p<0.001$ compared to adjuvant only negative control for both), while the IgGs from Pfs48/45-FL ( $3 \mu \mathrm{g})$ and 6C-Mut (10 $\mu \mathrm{g})$ groups showed $<10 \%$ reduction $(\mathrm{p}>0.87)$. To confirm the functional activities of anti-6C IgGs, the two samples were further tested at three concentrations in an independent assay (Fig. 3a and Supplementary Table S2, Feed \#2). Significant reduction in oocyst density was reproduced by IgGs tested at $750 \mu \mathrm{g} / \mathrm{mL}(>89 \%$ reduction, $\mathrm{p}<0.001)$. Although percentage reductions at lower concentrations $(250$ and $83 \mu \mathrm{g} / \mathrm{mL})$ did not reach significant level for both IgGs, a trend toward dose-dependent oocyst density reductions was observed. 
a

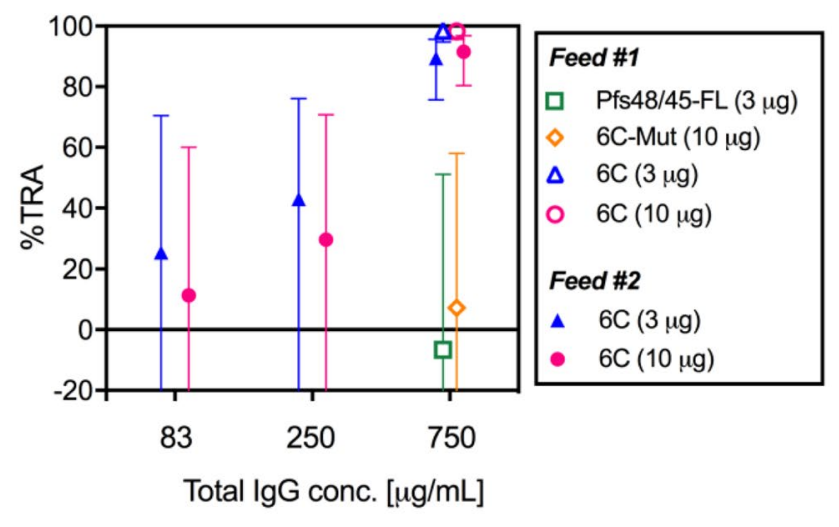

b ELISA
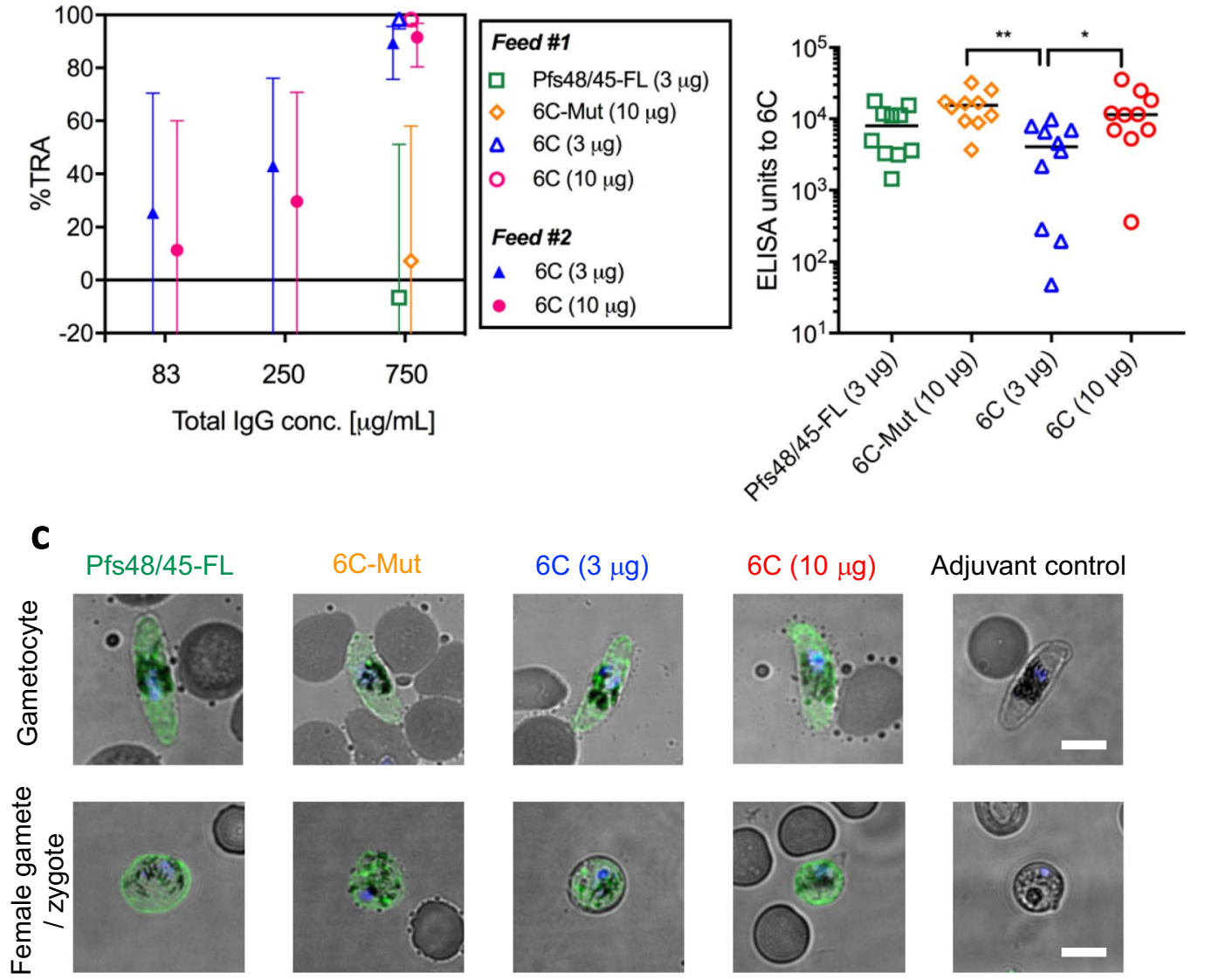

Figure 3. Immunological evaluations for recombinant Pfs $48 / 45$ constructs. Anti-Pfs $48 / 45$ antibodies were

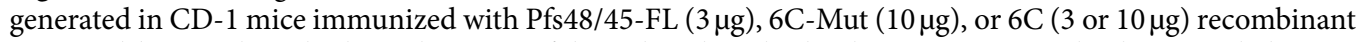
protein. (a) To evaluate biological activity of the induced antibodies by SMFA, an equal volume pooled antiserum sample was made for each group, and Protein G purified IgG tested at $750 \mu \mathrm{g} / \mathrm{mL}$ in the initial assay (Feed \#1). Anti-6C IgGs were retested in a second assay at 750, 250, and $83 \mu \mathrm{g} / \mathrm{mL}$ (Feed \#2). The best estimate and the $95 \%$ CI of \% inhibition (\%TRA) for each test IgG at each test condition are shown. (b) Anti-6C ELISA units were determined for individual antiserum samples. Individual and median ELISA units are shown. A significant difference among the four groups ( $\mathrm{p}=0.004$ by a Kruskal-Wallis test) was determined, and following Dunn's multiple comparison tests revealed that there were significant differences between 6CMut $(10 \mu \mathrm{g})$ and $6 \mathrm{C}(3 \mu \mathrm{g})$ groups $(\mathrm{p}=0.004)$, and between 6C $(3 \mu \mathrm{g})$ and $6 \mathrm{C}(10 \mu \mathrm{g})$ groups $(\mathrm{p}=0.037)$. (c) Immunofluorescence assay with fixed and permeabilized $P$. falciparum sexual-stage parasites. Purified total IgGs, which were used for SMFA, were incubated at $1 \mu \mathrm{g} / \mathrm{mL}$ with fixed mature gametocytes, gametes and zygotes. The antibody reactivity to the parasites are shown in green (Alexa Fluor 488), and DNA in blue (DAPI; 4',6-diamidino-2-phenylindole). The scale bar represents $5 \mu \mathrm{m}$.

The antisera raised against Pfs48/45-FL and 6C-Mut was then tested for reactivity via ELISA (Fig. 3b) to the $6 \mathrm{C}$ protein alone, the only immunogen which elicited biologically active antibodies. The anti-Pfs $48 / 45-\mathrm{FL}$ and anti-6C-Mut antisera both reacted to the $6 \mathrm{C}$ protein. To further investigate the mechanism of negative SMFA for anti-Pfs48/45-FL and anti-6C-Mut antibodies, immunofluorescence assay (IFA) was performed with fixed and permeabilized mature gametocytes, gametes/zygotes (Fig. 3c). As expected from the SMFA results, anti-6C IgGs reacted to sexual-stage parasites, and negative control IgG did not. Corresponding to the ELISA results, anti-Pfs48/45-FL and anti-6C-Mut antibodies also recognized sexual-stage parasites judged by IFA. Taken together, it is suggested that anti-Pfs48/45-FL and anti-6C-Mut antibodies recognized epitope(s), which are likely to be non-functional, but presented both in the recombinant protein and parasites.

Baculovirus expressed 6C fragment is homogeneous. Subsequent biochemical characterization focused on the $6 \mathrm{C}$ protein alone, given the successful induction of functional antibodies, while the 6C-Mut protein was utilized as a comparator. The yield of Pfs48/45-FL $(\sim 0.1 \mathrm{mg} / \mathrm{L})$ limited its availability for use in further biochemical characterization presented here.

Intact mass spectrometry and peptide mapping analysis. To determine whether the baculovirus-expressed recombinant $6 \mathrm{C}$ was glycosylated, or altered through other post translational modification, intact mass spectrometry 
a
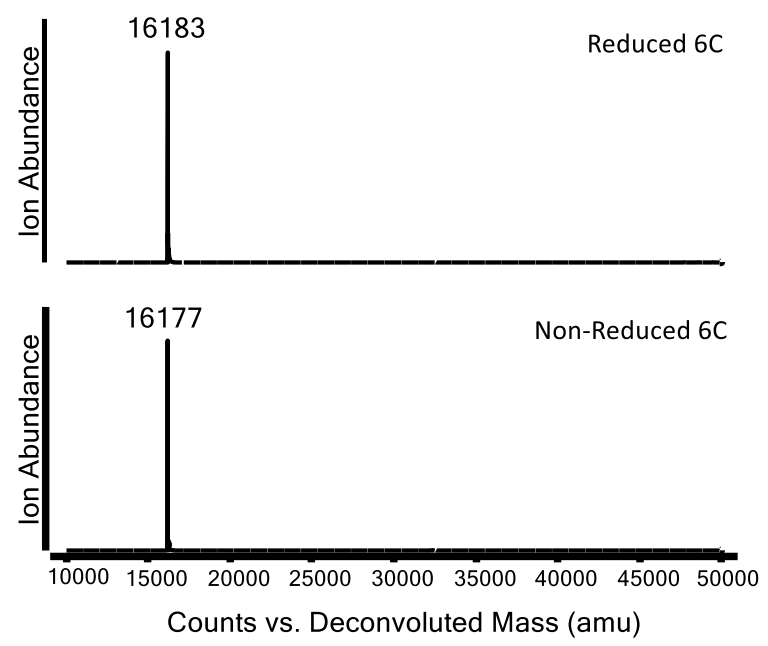

b

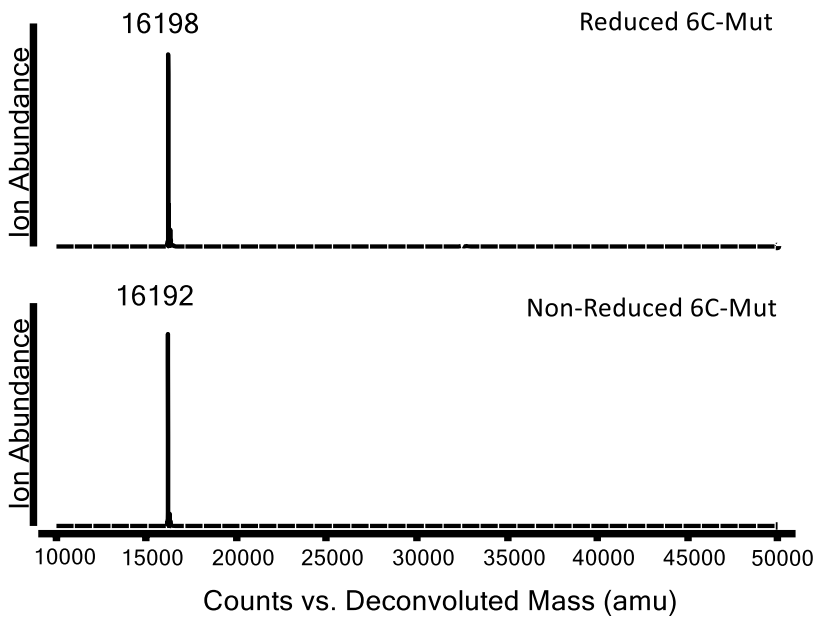

Figure 4. Representative intact mass analysis of Pfs48/45 6C and 6C-Mut proteins. Representative deconvoluted spectra $(10-50 \mathrm{kDa})$ under reduced and non-reduced conditions. (a) Intact mass analysis of reduced \& non-reduced $6 \mathrm{C}$ protein. Observed mass for reduced $6 \mathrm{C}$ was $16,183 \pm 1 \mathrm{Da}$ and non-reduced $6 \mathrm{C}$ was $16,177 \pm 1 \mathrm{Da}(\mathrm{n}=3)$ which corresponds to theoretical mass (assuming protein formed three intra-molecular disulfide bonds). (b) Intact mass analysis of reduced \& non-reduced 6C-Mut protein. Observed mass for reduced $6 \mathrm{C}$ was $16,198 \pm 1 \mathrm{Da}$ and non-reduced $6 \mathrm{C}$ was $16,192 \pm 1 \mathrm{Da}(\mathrm{n}=3)$ which corresponds to theoretical mass (assuming protein formed three intra-molecular disulfide bonds).

(MS) and LC-MS peptide mapping analyses were performed. The intact MS results (Fig. 4) indicated that the observed mass of the $6 \mathrm{C}$ fragment was $+115 \mathrm{Da}$ (Dalton) higher than its theoretical value of molecular mass. This mass difference was likely due to the inclusion of an $\mathrm{N}$-terminal Asp residue from the last amino acid of the signal peptide, as reported previously ${ }^{9,25}$. After correcting for the Asp addition at the N-terminal, the predominant intact mass of $16,177 \pm 1 \mathrm{Da}(\mathrm{n}=3)$ matched the prediction for the non-reduced form of the $6 \mathrm{C}$ fragment. Upon reduction, an increase of six Daltons was observed, to $16,183 \pm 1 \mathrm{Da}(\mathrm{n}=3)$, matching the theoretical reduced form (Fig. 4a), and confirming the formation of three intra-molecular disulfide bonds. LC-MS peptide mapping (Supplementary Fig. S1) of the reduced and alkylated 6C fragment, utilizing GluC and Trypsin for proteolysis, confirmed $98 \%$ of the $6 \mathrm{C}$ sequences and no post-translational modifications were identified. These results combined demonstrated that tunicamycin effectively inhibited glycosylation of the non-mutated 6C molecule. Further, the intact mass of 6C-Mut (Fig. 4b) shows the oxidized and reduced form both matched the theoretical mass $16,192 \pm 1 \mathrm{Da}$ and $16,198 \pm 1 \mathrm{Da}(\mathrm{n}=3)$ with an Asp residue present at the $\mathrm{N}$-terminus. In addition, these data demonstrate that the mutation of two sites effectively eliminated glycosylation of 6C-Mut.

Chromatography analysis of $6 \mathrm{C}$ and $6 \mathrm{C}-\mathrm{Mut}$ proteins. Size exclusion (SE)-HPLC indicated that 6C was homogeneous and monomeric (Fig. 5a) eluting as a single peak at $\sim 14 \mathrm{~min}$. This retention time was consistent with a monomer based on the elution of gel filtration molecular weight (MW) standards. In contrast, 6C-Mut contained 
a

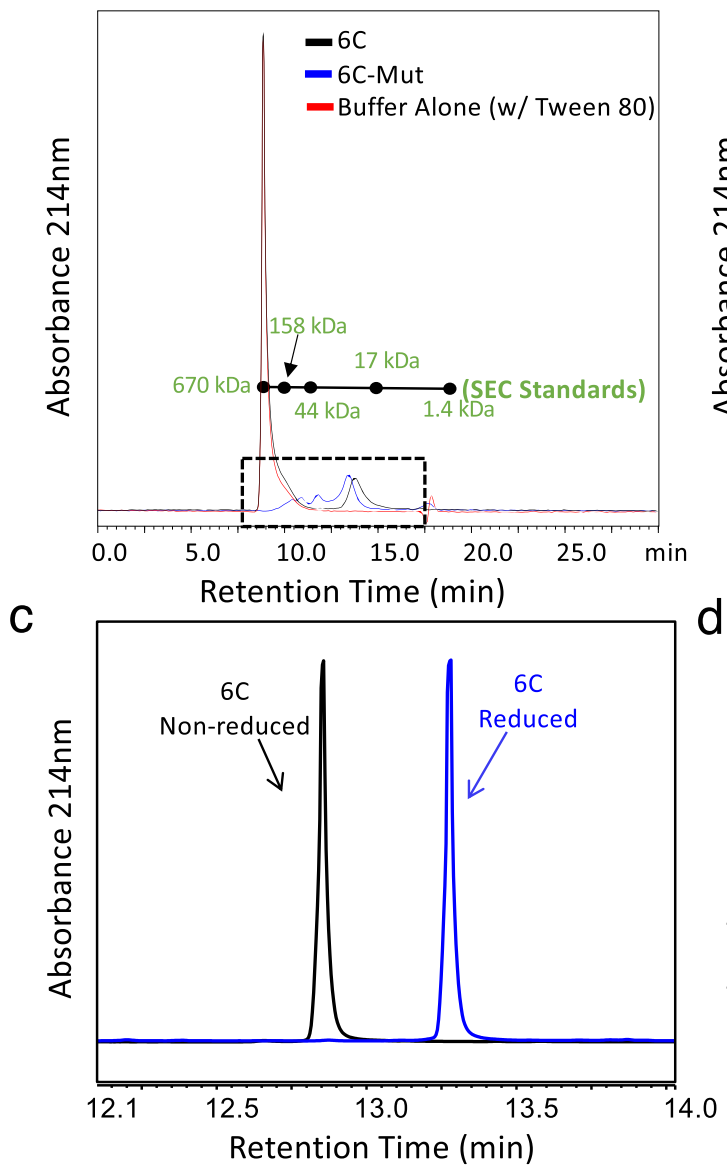

b

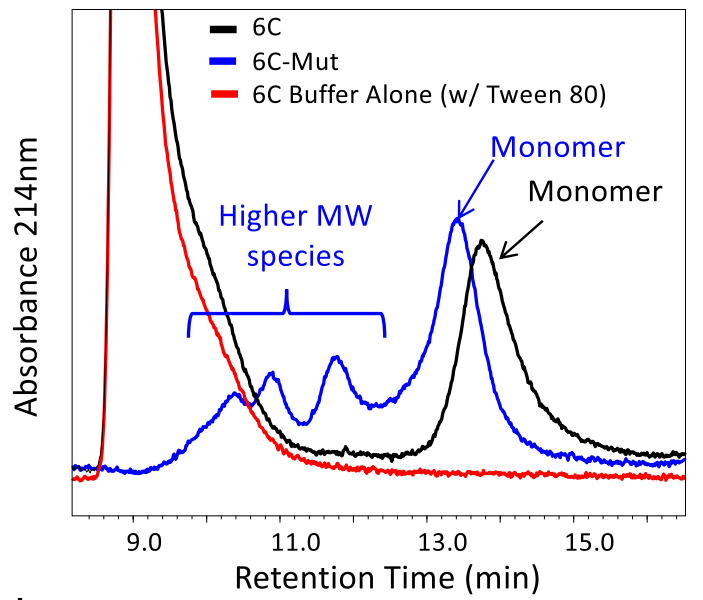

d

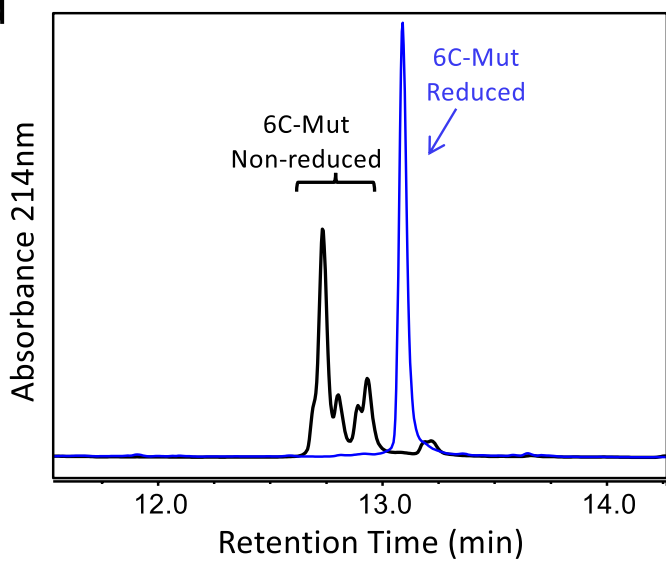

Figure 5. Representative chromatography analysis of Pfs48/45 6C and 6C-Mut proteins. (a) SE-HPLC analysis of 6C (black trace), 6C-Mut (blue trace) and buffer alone (red trace). Molecular weight retention times indicated according to Bio-Rad gel filtration standards. (b) Inset of SE-HPLC analysis with higher molecular weight and monomer peaks indicated. (c) RP-UHPLC of 6C (non-reduced and reduced). (d) RP-UHPLC of 6C-Mut (nonreduced and reduced).

at least four species between $\sim 670-17 \mathrm{kDa}$ with only $59 \%$ monomeric protein (Fig. $5 \mathrm{~b}$ ). It should also be noted that substantial absorbance was observed within $8.5-11 \mathrm{~min}$ in the $6 \mathrm{C}$ sample, which was likely due to the high concentration of Tween 80 in the final formulation buffer.

In the reversed phase (RP)-HPLC analysis, the 6C protein was confirmed to be homogeneous with a single peak eluting under non-reducing or reducing conditions, at $\sim 12.8$ or $\sim 13.3 \mathrm{~min}$, respectively (Fig. $5 \mathrm{c}$ ). Consistent with the SE-HPLC results, the 6C-Mut exhibited multiple species via RP-HPLC. Under non-reducing conditions, multiple peaks were observed for 6C-Mut (between 12.5-13.3 $\mathrm{min}$ ) in the chromatogram. However, under reducing conditions, a single peak ( $13.1 \mathrm{~min})$ was observed. These results strongly suggest that the non-reduced form of the 6C-Mut contains multiple species with different disulfide linkages (Fig. 5d).

Isoelectric focusing. The biologically active 6C was evaluated for presence of isoforms. A single band was observed in the IEF gel for non-reduced 6C (Supplementary Fig. S2), which migrated between the 4.5-5.2 pI markers, a result consistent with the theoretical pI of 5.17. This result further confirmed that the $6 \mathrm{C}$ protein was present in a singular form.

The $6 \mathrm{C}$ protein as expressed in baculovirus demonstrates predicted disulfide bond linkages. Given the importance of proper disulfide bond formation to ensure the native configuration of Plasmodium proteins and subsequent induction of functional antibodies, the disulfide linkages were investigated by two methods. First, to simply confirm the formation of disulfide bonds, the number of thiol groups exposed on the protein surface was measured. The analysis showed that $6 \mathrm{C}$ contains little or no free thiol $(<5 \%)$ under both native-like and denaturing conditions (with and without $3 \mathrm{M}$ guanidine- $\mathrm{HCl}$ ), suggesting that all six cysteines were fully oxidized and likely paired by disulfides. Second, to discern the exact pairing of cysteines in the 6C protein, disulfide mapping was performed. The non-reduced and reduced $6 \mathrm{C}$ were subjected to an optimized thermolysin digestion method and the resulting peptides were analyzed by LC/MS peptide mapping. Table 1 shows the disulfide linked peptides that supported the pairing of the three disulfide bonds, primarily between $\mathrm{Cys}^{298}(\mathrm{C} 1)$ and $\mathrm{Cys}^{327}(\mathrm{C} 2)$, between $\mathrm{Cys}^{344}(\mathrm{C} 3)$ and $\mathrm{Cys}^{412}(\mathrm{C} 6)$ and between $\mathrm{Cys}^{352}(\mathrm{C} 4)$ and $\mathrm{Cys}^{410}$ (C5) along with the predicted theoretical 


\begin{tabular}{|c|c|c|c|c|c|c|c|c|}
\hline \begin{tabular}{|l|} 
RT \\
Min
\end{tabular} & $\begin{array}{l}\text { Expected monoisotopic } \\
\text { mass Da }\end{array}$ & Identified peptide & Cys involved & $\begin{array}{l}\text { Mass observed } \\
\mathrm{m} / \mathrm{z} \text { 6C }\end{array}$ & $\begin{array}{l}\text { Charge } \\
\text { state }\end{array}$ & $\begin{array}{l}\text { Calculated } \\
\text { mass M }\end{array}$ & $\begin{array}{l}\text { Delta mass } \\
\text { ppm }\end{array}$ & Area \\
\hline \multirow{2}{*}{31.0} & \multirow{2}{*}{975.3903} & \multirow{2}{*}{ I295-N299/I325-N328 } & \multirow{2}{*}{$\mathrm{C} 1+\mathrm{C} 2(\mathrm{Y} 3+\mathrm{Y} 12)$} & 488.6922 & 2 & \begin{tabular}{|l|}
975.3688 \\
\end{tabular} & \multirow{2}{*}{15.5} & \multirow{2}{*}{416} \\
\hline & & & & 976.3895 & 1 & 975.3817 & & \\
\hline \multirow{2}{*}{36.3} & \multirow{2}{*}{1074.4587} & \multirow{2}{*}{ V294-N299/I325-N328 } & \multirow{2}{*}{$\mathrm{C} 1+\mathrm{C} 2(\mathrm{Y} 2-3+\mathrm{Y} 12)$} & \begin{tabular}{|l|}
538.2266 \\
\end{tabular} & 2 & 1074.4376 & \multirow{2}{*}{12.8} & \multirow{2}{*}{674} \\
\hline & & & & 1075.4601 & 1 & 1074.4523 & & \\
\hline 37.2 & 1157.4594 & I295-N299/L342-D347 & $\mathrm{C} 1+\mathrm{C} 3(\mathrm{Y} 3+\mathrm{Y} 17)$ & 579.7368 & 2 & 1157.4580 & 1.2 & 15 \\
\hline 42.4 & 1256.5278 & V294-N299/L342-D347 & $\mathrm{C} 1+\mathrm{C} 3(\mathrm{Y} 2-3+\mathrm{Y} 17)$ & \begin{tabular}{|l}
629.2675 \\
\end{tabular} & 2 & 1256.5194 & 6.7 & 7 \\
\hline 78.0 & 1246.5475 & I295-N299/ I348-F353 & $\mathrm{C} 1+\mathrm{C} 4(\mathrm{Y} 3+\mathrm{Y} 18-20)$ & \begin{tabular}{|l|}
624.2809 \\
\end{tabular} & 2 & 1246.5462 & 1.1 & 2 \\
\hline 86.5 & 1321.5683 & L342-D347/I348-F353 & $\mathrm{C} 3+\mathrm{C} 4(\mathrm{Y} 17+\mathrm{Y} 18-20)$ & \begin{tabular}{|l|}
661.7900 \\
\end{tabular} & 2 & 1321.5644 & 3.0 & 4 \\
\hline \multirow{2}{*}{28.1} & \multirow{2}{*}{1563.7749} & \multirow{2}{*}{ L342-D347/I411-S418 } & \multirow{2}{*}{$\mathrm{C} 3+\mathrm{C} 6(\mathrm{Y} 17+\mathrm{Y} 38)$} & \begin{tabular}{|l|}
782.8868 \\
\end{tabular} & 2 & 1563.7580 & \multirow{2}{*}{11.8} & \multirow{2}{*}{1257} \\
\hline & & & & 522.2595 & 3 & 1563.7550 & & \\
\hline \multirow{2}{*}{79.5} & \multirow{2}{*}{926.3878} & \multirow{2}{*}{ I348-C352/ F408-C410 } & \multirow{2}{*}{$\mathrm{C} 4+\mathrm{C} 5(\mathrm{Y} 18-19+\mathrm{Y} 37)$} & 464.1954 & 2 & 926.3752 & \multirow{2}{*}{5.6} & \multirow{2}{*}{243} \\
\hline & & & & \begin{tabular}{|l|}
927.3979 \\
\end{tabular} & 1 & \begin{tabular}{|l|l|}
926.3901 \\
\end{tabular} & & \\
\hline \multirow{2}{*}{92.5} & \multirow{2}{*}{1073.4562} & \multirow{2}{*}{ I348-F353/F408-C410 } & \multirow{2}{*}{$\mathrm{C} 4+\mathrm{C} 5(\mathrm{Y} 18-20+\mathrm{Y} 37)$} & 537.7386 & 2 & 1073.4616 & \multirow{2}{*}{-4.3} & \multirow{2}{*}{951} \\
\hline & & & & \begin{tabular}{|l|}
1074.468 \\
\end{tabular} & 1 & 1073.4601 & & \\
\hline 37.8 & 1505.7964 & I348-C352/I411-S418 & C4 + C6 (Y18-19+Y38) & \begin{tabular}{|l}
753.9022 \\
\end{tabular} & 2 & 1505.7888 & 5.1 & 4 \\
\hline \multirow{2}{*}{63.2} & \multirow{2}{*}{1652.8630} & \multirow{2}{*}{ I348-F353/I411-S418 } & \multirow{2}{*}{$\mathrm{C} 4+\mathrm{C} 6(\mathrm{Y} 18-20+\mathrm{Y} 38)$} & \begin{tabular}{|l|}
827.4354 \\
\end{tabular} & 2 & 1652.8552 & \multirow{2}{*}{6.5} & \\
\hline & & & & 551.9576 & 3 & 1652.8493 & & 10 \\
\hline 182 & 13817058 & I325-N328/4411-S418 & 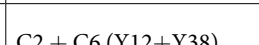 & \begin{tabular}{|l|}
691.8593 \\
\end{tabular} & 2 & 1381.7030 & -0 & 12 \\
\hline 18.2 & $1381 . / 058$ & $1325-N 328 / 1411-3418$ & $\mathrm{C} 2+\mathrm{Co}(\mathrm{Y} 12+\mathrm{Y} 38)$ & 461.5777 & 3 & 1381.7096 & -0.4 & 12 \\
\hline
\end{tabular}

Table 1. Disulfide peptides observed in the thermolysin digest of 6C. Disulfide peptides and bonds observed for $6 \mathrm{C}$ in the thermolysin digest are presented. The delta mass error is the average of the errors for each of the charge state. Theoretical peptides of 6C are shown in Table 2.

peptide fragments (Table 2). A schematic representation of the amino acid sequence and elucidated disulfide mapping is provided in Fig. 6 . This mapped pairing of cysteines for the baculovirus $6 \mathrm{C}$ matched the predicted disulfide bonding pattern of the cysteine-rich motif ${ }^{13}$.

\section{Discussion}

In these studies, we report for the first time the expression of Pfs $48 / 45$ proteins using the baculovirus system and their biological and biochemical evaluation. After expression, all three proteins were found in the cell pellet. This result suggests that in insect cells the inclusion of a signal peptide in the construct is not sufficient to direct secretion for the Pfs $48 / 45$ derived sequences. Further, no post-translational modifications were observed, indicating that $\mathrm{N}$-glycosylation was successfully inhibited by the incorporation of tunicamycin during baculovirus expression. While produced in low yields, the Pfs $48 / 45$ full-length protein was expressed and reacted to conformational monoclonal antibodies, though it did not induce functional antibodies as determined by SMFA. Production of the $6 \mathrm{C}$ protein resulted in an un-optimized yield of $3 \mathrm{mg} / \mathrm{L}$ which allowed for detailed analysis of the biochemical properties.

We attempted to produce Pfs $48 / 45$ proteins in the non-glycosylated state presumably present in the parasite. In both the 6C and 6C-Mut proteins, $N$-glycosylation was successfully prevented by two independent approaches. The addition of $1 \mu \mathrm{g} / \mathrm{mL}$ tunicamycin resulted in undetectable glycosylation for the $6 \mathrm{C}$ protein as evaluated by intact mass spectrometric analysis and LC-MS peptide mapping. Further, the mutation of the two high probability glycosylation sites was also successful in preventing $N$-glycosylation for the 6C-Mut protein, as indicated by no detectable post translational modification based on intact mass. However, the mutation strategy did not produce a properly folded protein and multiple species were present as observed by SE and RP-HPLC. 6C-Mut was also not recognized by the conformational monoclonal antibody 85RF45.1, and it did not induce transmission reducing activity in mice.

Tunicamycin was previously used by Tonkin et al. to produce a secreted, soluble, non-glycosylated malaria antigen, Pf12, in the High Five cell/baculovirus expression system ${ }^{30}$. In those studies, the concentration of tunicamycin was $0.2 \mu \mathrm{g} / \mathrm{mL}$ and served as the basis for the concentrations tested here. They also reported in those studies that protein expression was severely attenuated with the addition of tunicamycin, consistent to our observations (Supplementary Table S1).Protein translocation through the ER, including its mechanisms and attenuation, while not fully known - have been proposed and described ${ }^{31}$. In the case of Pfs $48 / 45$ proteins produced here, even though the signal sequence was recognized by signal recognition particle and later cleaved, there was no guarantee of secretion. Similarly, Klaus et al. also faced an inefficient secretion of a recombinant vascular endothelial growth factor C (VEGF-C) to baculovirus/insect culture medium and was unable to improve secretion by altering culture conditions or signal peptides ${ }^{32}$. The lysate of the baculovirus infected insect cells, however, still constituted a valuable source of biologically active proteins $s^{32}$. Although the proteins reported here were successfully extracted from cell pellets using sarkosyl, a systematic and thorough evaluation of various extraction reagents and stabilization excipients were not explored, which merit further evaluation as part of future work.

In recent studies, Kundu et al. cloned the 6C fragment in HEK 293 cells without genetic modification of the $\mathrm{N}$-glycosylation sites, N299 and N303, and the resulting crystal structure revealed that N303 is indeed 


\begin{tabular}{|c|c|c|c|}
\hline $\begin{array}{l}\text { Fragment } \\
\text { number }\end{array}$ & Amino acid & $\begin{array}{l}\text { Theoretical } \\
\text { mass }\end{array}$ & Amino acid \\
\hline Y1 & $\mathrm{D}+291-293$ & 500.26 & DEKK \\
\hline $\mathrm{Y} 2$ & 294 & 117.08 & $\mathrm{~V}$ \\
\hline Y3 & $295-299$ & 542.23 & IHGCN \\
\hline Y4 & $300-303$ & 453.19 & FSSN \\
\hline Y5 & 304-309 & 657.34 & VSSKHT \\
\hline Y6 & $310-313$ & 468.19 & FTDS \\
\hline Y7 & $314-315$ & \begin{tabular}{|l|}
246.12 \\
\end{tabular} & LD \\
\hline Y8 & $316-317$ & 218.13 & IS \\
\hline Y9 & 318 & 131.09 & $\mathrm{~L}$ \\
\hline Y10 & $319-322$ & 434.16 & VDDS \\
\hline Y11 & $323-324$ & 226.11 & $\mathrm{AH}$ \\
\hline Y12 & $325-328$ & 435.18 & ISCN \\
\hline Y13 & $329-330$ & 254.14 & $\mathrm{VH}$ \\
\hline Y14 & $331-338$ & 986.48 & LSEPKYNH \\
\hline Y15 & 339 & \begin{tabular}{|l|}
131.09 \\
\end{tabular} & $\mathrm{~L}$ \\
\hline Y16 & $340-341$ & 174.1 & VG \\
\hline Y17 & $342-347$ & 617.25 & LNCPGD \\
\hline Y18 & 348 & 131.09 & I \\
\hline Y19 & $349-352$ & 446.18 & IPDC \\
\hline Y20 & 353 & 165.08 & $\mathrm{~F}$ \\
\hline Y21 & $354-355$ & 293.14 & FQ \\
\hline Y22 & $356-363$ & 979.41 & VYQPESEE \\
\hline Y23 & $364-368$ & \begin{tabular}{|l|}
558.26 \\
\end{tabular} & LEPSN \\
\hline $\mathrm{Y} 24$ & 369 & 131.09 & I \\
\hline Y25 & $370-371$ & 280.14 & VY \\
\hline Y26 & $372-375$ & 461.21 & LDSQ \\
\hline Y27 & $376-377$ & 245.14 & IN \\
\hline Y28 & $378-380$ & 303.14 & IGD \\
\hline Y29 & $381-386$ & 830.33 & IEYYED \\
\hline Y30 & $387-392$ & \begin{tabular}{|l|}
633.26 \\
\end{tabular} & AEGDDK \\
\hline Y31 & $393-394$ & 259.19 & $\mathrm{IK}$ \\
\hline Y32 & 395 & 131.09 & $\mathrm{~L}$ \\
\hline Y33 & $396-397$ & 222.1 & FG \\
\hline Y34 & 398 & 131.09 & I \\
\hline Y35 & $399-401$ & 261.13 & VGS \\
\hline Y36 & $402-407$ & 645.37 & IPKTTS \\
\hline Y37 & $408-410$ & 369.14 & FTC \\
\hline Y38 & $411-418$ & \begin{tabular}{|l|l|}
948.54 \\
\end{tabular} & ICKKDKKS \\
\hline Y39 & $419-420$ & 252.11 & $\mathrm{AY}$ \\
\hline Y40 & $421-422$ & 250.1 & MT \\
\hline Y41 & $423-424$ & 218.13 & $\mathrm{VT}$ \\
\hline Y42 & $425-427+6 \mathrm{H}$ & 1155.51 & IDSHННННН \\
\hline
\end{tabular}

Table 2. Theoretical fragments for thermolysin digest of 6C.

glycosylated ${ }^{16}$. After EndoH treatment, the N-acetylglucosamine attached to N303 forms H-bonds with D390 and D391 of the 6C molecule. On the other hand, N299 was found not to be glycosylated with the side chain of N299 involved in $\mathrm{H}$ bonding with S301. These two N-glycosylation sites (N299 and N303) are not directly involved in the binding of $6 \mathrm{C}$ to $85 \mathrm{RF} 45.1$, but the results reported here, together with Kundu et al, suggest that amino acid sequence at these sites can play important roles in the proper folding of $6 \mathrm{C}^{16}$. While the glycosylation at these sites are not expected to occur in the parasite, our results also suggest that mutation of the primary sequence may also disturb higher order structure.

In this work, the $6 \mathrm{C}$ protein was the only protein that elicited transmission-reducing antibodies in mice. The 6C was also found to be properly folded and homogeneous in terms of charge, size and conformation. In contrast, the 6C-Mut was likely not in a native conformation, supported by a lack of $85 \mathrm{RF} 45.1$ binding and the presence of multiple chromatographic forms. Therefore, it is not surprising that no sera with transmission-reducing activity were identified for the 6C-Mut. It is not clear why the full-length version did not induce transmission reducing activity; perhaps potent epitope in the $6 \mathrm{C}$ domain was masked or out competed by other regions of the protein. 


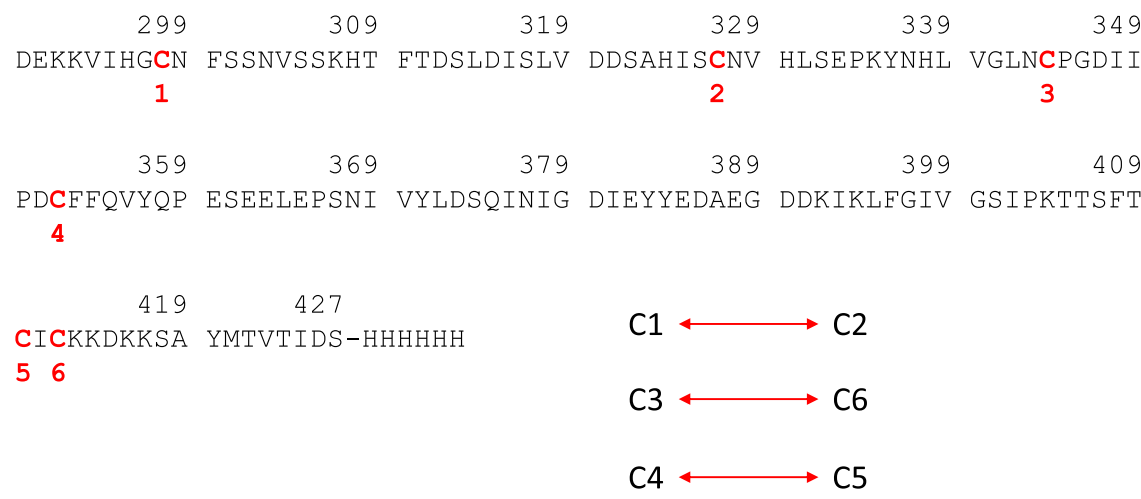

Figure 6. Disulfide pairing of Baculovirus expressed 6C as experimentally confirmed by LC/MS peptide mapping. $\mathrm{Cys}^{298}, \mathrm{Cys}^{327}, \mathrm{Cys}^{344}, \mathrm{Cys}^{352}, \mathrm{Cys}^{410}$ and $\mathrm{Cys}^{412}$ were denoted as $\mathrm{C} 1$ through C6. The majority of disulfide bonds in $6 \mathrm{C}(\geq 98 \%)$ are connected between $\mathrm{C} 1$ and $\mathrm{C} 2$, between $\mathrm{C} 3$ and $\mathrm{C} 6$ and between $\mathrm{C} 4$ and $\mathrm{C} 5$.

Our results on expression of full-length Pfs48/45 is consistent with the many previous attempts to generate this recombinant protein. While some of the Pfs $48 / 45$-FL protein was likely correctly folded in our analyses, additional strategies are needed to study this protein in greater detail before it may be considered as a viable vaccine candidate.

Given the presence of a pure, homogeneous protein for $6 \mathrm{C}$ fragment, coupled with the ability to elicit transmission reducing antibodies, we further confirmed the disulfide pairing of the recombinant protein. Our initial effort in mapping disulfides using GluC and trypsin digestion of non-reduced and reduced, alkylated $6 \mathrm{C}$ was not successful due to proximity of $\mathrm{Cys}^{410}$ and $\mathrm{Cys}^{412}$ (data not shown). Subsequently, improved methods were developed using thermolysin digestion which cleaves at the $\mathrm{N}$-terminal of the hydrophobic amino acid residues ${ }^{33}$. Here, thermolysin cleaved multiple positions between $\mathrm{Cys}^{344}$ and $\mathrm{Cys}^{412}$, including $\mathrm{Cys}^{410}$ and Cys ${ }^{412}$ at the amino acid residue 411 (isoleucine). As shown in Table 1 and Fig. 6, Cys ${ }^{410}(\mathrm{C} 5)$ and $\mathrm{Cys}^{412}$ (C6) are isolated to different peptides after thermolysis digestion, allowing us to accurately map the C3 and C6 connection and C4 and C5 connection unequivocally. These results coupled with the biochemical analysis (SE-HPLC, RP-HPLC, IEF) indicate the $6 \mathrm{C}$ protein is expressed in baculovirus as a homogeneous and properly folded molecule.

In this report, we demonstrated that baculovirus can express a properly folded $6 \mathrm{C}$ fragment without a fusion partner and tunicamycin was successful in producing a homogeneous, non-glycosylated 6C. The reported assessment of baculovirus-produced $6 \mathrm{C}$ represents a first step towards developing a TBV vaccine that targets the Pfs $48 / 45$ protein.

\section{Methods}

Baculovirus expression constructs. Three constructs of the Pfs $48 / 45$ protein were prepared for expression in baculovirus. "6C," the C-terminal sequence of the gametocyte surface protein Pfs48/45 of 3D7 strain (ACCESSION Q816T1), containing six cysteines as part of a predicted cysteine-rich domain (aa 291-427); "6CMut," which has two mutations of $N$-glycosylation sites, N299Q and N303D, incorporated in the 6C construct (aa 291-427); and "Pfs48/45-FL," a full-length Pfs48/45 without the signal peptide and GPI anchor (aa 28-427).

Codon optimization for baculovirus expression was performed by DNA2.0 (now ATUM) with an additional $\mathrm{N}$-terminal secretion signal (MKFLVNVALVFMVVYISYIYAD from Honeybee Melittin) and a C-terminal hexa-histidine tag. Genes were cloned into pFastBac donor vector (Invitrogen) with BamHI (5') and EcoRI ( $\left.3^{\prime}\right)$ sites. The resulting plasmid pFastBac- $48 / 45$ constructs were sequence verified. Production of recombinant viruses followed the same procedure as described earlier ${ }^{25}$.

Expression and purification of Pfs48/45 baculovirus proteins. Super Sf9 cells were seeded at $1 \times 10^{6}$ cells/mL in ESF 921 medium (Expression Systems, CA). MOI of one was used to infect a 10 L super Sf9 wave culture and tunicamycin was added at a final concentration of $1 \mu \mathrm{g} / \mathrm{mL}$. At $96 \mathrm{~h}$ post infection, culture was harvested, and the cell pellet was resuspended in lysis buffer $(20 \mathrm{mM}$ Tris- $\mathrm{HCl}, 2 \%$ sarkosyl, protease inhibitor tablets, $\mathrm{pH}$ 8.0) and processed with a high-pressure homogenizer (Panda plus). The soluble fraction was recovered by centrifugation, diluted with $20 \mathrm{mM}$ Tris- $\mathrm{HCl}, 300 \mathrm{mM} \mathrm{NaCl}, 5 \mathrm{mM}$ imidazole, $\mathrm{pH} 8.0$ (buffer A) and clarified with $0.22 \mu \mathrm{m}$ filtration.

The clarified supernatant was loaded on a $20 \mathrm{~mL}$ Ni-NTA column $(1.6 \times 10 \mathrm{~cm}$, His-60, Clontech). The wash steps were performed with ten column volume $(\mathrm{CV})$ of Buffer A with $20 \mathrm{mM}$ imidazole and $0.2 \%$ Tween- 80 . The protein was eluted with a 20 to $100 \%$ gradient of buffer B $(20 \mathrm{mM}$ Tris- $\mathrm{HCl}, 500 \mathrm{mM} \mathrm{NaCl}, 500 \mathrm{mM}$ imidazole, $0.2 \%$ Tween-80, pH 8.0). Pooled eluents from Ni-NTA column were loaded onto a Superdex 75 column (GE Healthcare, $2.6 \times 60 \mathrm{~cm}, 300 \mathrm{~mL}$ ) and buffer exchanged into $20 \mathrm{mM}$ HEPES, $150 \mathrm{mM} \mathrm{NaCl}$ containing $0.2 \%$ Tween-80 (pH 7.5). For the Pfs48/45-FL protein, a Superdex 200 was used after His- 60 column. The eluents were collected, analyzed with SDS-PAGE, and final pool selected based on purity.

SDS-PAGE and Western blotting (anti-His). SDS-PAGE and Western blot with Penta-His antibody (Qiagen) were performed as described earleir? 
Western blotting (mAb 85RF45.1). Following SDS-PAGE, proteins were transferred onto PVDF membrane and blocked in 1\% skim milk in Tris buffered saline containing $0.05 \%$ Tween-20 (TBST) at room temperature for one hour. Primary antibody at a 1:1,000 dilution of mAb 85RF45.1 $(1 \mathrm{mg} / \mathrm{mL})$ in TBST was added and incubated for $1 \mathrm{~h}$ at room temperature. Membranes were washed with TBST (3X for $10 \mathrm{~min}$ ) and secondary antibody, 1:5,000 dilution of goat anti-rat IgG-alkaline phosphatase (Bio-Rad) in TBST was incubated at room temperature for $1 \mathrm{~h}$. Membranes were washed with TBST (3X for $10 \mathrm{~min}$ ), developed using alkaline phosphatase substrate kit (Bio-Rad), followed by a water wash to stop the reaction and air-dried.

Protein concentration determination. Recombinant $\mathrm{Pfs} 48 / 45$ proteins contain no tryptophan residue and UV at $\mathrm{A}_{280}$ was not ideal for protein determination. The BCA assay kit (Thermo) was therefore used according to manufacturer's instructions.

Mouse immunization. All animal experiments were performed in accordance with the animal study protocol (LMVR 10E) which was reviewed and approved by the NIAID Animal Care and Use Committee. CD-1 mice $(\mathrm{n}=10$ per group) were immunized intramuscularly with Pfs48/45-FL ( $3 \mu \mathrm{g}$ per dose), 6C-Mut (10 $\mu \mathrm{g})$ or $6 \mathrm{C}$ (3 or $10 \mu \mathrm{g}$ ) recombinant protein formulated with Montanide ISA720 (SEPPIC Inc., Fairfield, NJ) on days 0 and 21. Serum samples were collected on day 42 . As a negative control, a group of mice $(n=10)$ were immunized with ISA720 alone on the same schedule.

IgG purification, SMFA and ELISA. The biological activity of anti-Pfs48/45 IgGs was tested by SMFA at $750 \mu \mathrm{g} / \mathrm{mL}$ with complement in the first assay, and the two positive IgGs (anti-6C IgGs) from the first assay were further evaluated at 750, 250 and $83 \mu \mathrm{g} / \mathrm{mL}$ with complement in a second assay. In each assay, the anti-adjuvant IgG was tested at $750 \mu \mathrm{g} / \mathrm{mL}$ as a negative control. The standardized methodology for performing the SMFA has been described previously ${ }^{34}$. In brief, 16-18-day old gametocyte cultures of the $P$. falciparum NF54 line were mixed with test IgGs at indicated concentrations, and fed to Anopheles stephensi mosquitoes. All feeding experiments were performed with human complement and $n=20$ mosquitoes per group were examined 8 days after feeding experiment for oocyst count.

Basic methodology of regular ELISA has been described elsewhere ${ }^{35}$. For Pfs48/45-FL and 6C-Mut groups, individual antisera were tested against both the corresponding immunogen and $6 \mathrm{C}$ protein. For $6 \mathrm{C}(3 \mu \mathrm{g})$ and 6C $(10 \mu \mathrm{g})$ groups, ELISA units were determined against the 6C protein alone. The antisera from ISA720 control group were tested against all three proteins.

Statistics. Percent inhibition in mean oocyst intensity (\%TRA) of a test sample was calculated against a control sample examined in the same feeding experiment. The best estimate and 95\% confidence intervals (95\%CIs) of $\% \mathrm{TRA}$, and p-value (whether the inhibition is significantly different from no inhibition) for each test condition was calculated using a negative binomial model with zero inflation model, as described previously ${ }^{36}$. All statistical analysis was performed in $\mathrm{R}$ (version 3.4.1) or Prism 7 (GraphPad Software), and p-values $<0.05$ were considered significant.

Immunofluorescence assay (IFA). The IFA was performed as described previously ${ }^{9}$ with minor modifications. In this study, mature gametocytes were incubated with $100 \%$ human serum at $19^{\circ} \mathrm{C}$ for 20 minutes to induce gametes and zygotes, and IFA slides prepared using the mixture of gametocytes, gametes and zygotes. The cells were fixed and permeabilized with a 1:1 mixture of methanol-acetone, and the slides were blocked by PBS with 3\% skim milk. The primary antibodies (purified IgG from each group, which were used for SMFA) were incubated at $1 \mu \mathrm{g} / \mathrm{mL}$ for 1 hour at $37^{\circ} \mathrm{C}$, then stained with secondary antibody and DAPI (4',6-diamidino-2-phenylindole) as described previously. All images were captured on a Lecia SP8 confocal microscope with LAS X software version 3.5.5.19976. Images were deconvolved using Huygens essential software version 19.04.0p2 64b.

Intact mass spectrometry. The $6 \mathrm{C}$ or $6 \mathrm{C}$-Mut protein was incubated in either water (non-reduced) or $50 \mathrm{mM}$ DTT (reduced) for $30 \mathrm{~min}$ at $60^{\circ} \mathrm{C}$ and desalted on a C4 column (Waters Corp.) prior to MS analysis. The intact mass of the protein was measured using a Model 6230B time-of-flight (ToF) mass spectrometer (Agilent Technologies). MS ${ }^{1}$ spectra were acquired over a mass range of $400-3200 \mathrm{~m} / \mathrm{z}$, with a scan rate of one spectra/sec. Protein deconvolution was performed using MassHunter (Agilent Technologies).

LC-MS peptide mapping. Recombinant 6C was bound to a strong anion exchange spin filter (Pierce), washed with phosphate and eluted with $1 \mathrm{M} \mathrm{NaCl}$. The sample was reduced with $5 \mathrm{mM}$ DTT for $30 \mathrm{~min}$ at $60^{\circ} \mathrm{C}$ and alkylated with $10 \mathrm{mM}$ iodoacetamide at $37^{\circ} \mathrm{C}$ for $30 \mathrm{~min}$ in the dark. The reduced and alkylated $6 \mathrm{C}$ was digested with $1: 1$ mixture of GluC and Trypsin at $37^{\circ} \mathrm{C}$ overnight and subjected to LC/MS for peptide identification using an Ultimate 3000 UHPLC system (Thermo Scientific) with a $1.7 \mu \mathrm{m} \mathrm{C18} \mathrm{column}(2.1 \times 150 \mathrm{~mm}$, Thermo) at a flow rate of $0.2 \mathrm{~mL} / \mathrm{min}$. C18 column and autosampler temperatures were set at $50^{\circ} \mathrm{C}$ and $5{ }^{\circ} \mathrm{C}$, respectively. Mobile phase (A) consisted of Water with $0.04 \%$ trifluoroacetic acid (TFA) and mobile phase (B) consisted of Acetonitrile with $0.04 \%$ TFA. MS range of $400-1900 \mathrm{~m} / \mathrm{z}$ was used. Peptides were identified using $\mathrm{MS}^{1}$ and $\mathrm{MS}^{2}$ data and PepFinder (Thermo Scientific).

SE-HPLC. SE-HPLC used the same method as described earlier ${ }^{9}$ with the exception of the mobile phase, which was $20 \mathrm{mM}$ HEPES, $150 \mathrm{mM} \mathrm{NaCl}$, $\mathrm{pH} 7.5$.

RP-HPLC. Proteins were incubated with either $10 \%$ water (non-reduced) or $100 \mathrm{mM}$ DTT (reduced) for $30 \mathrm{~min}$ at $60^{\circ} \mathrm{C}$, centrifuged for $5 \mathrm{~min}$ at $14,000 \times \mathrm{g}$, and then subjected to RP-UHPLC using the same method as described earlier ${ }^{25}$. Triplicate experiments were performed. 
Isoelectric focusing. Precast CleanGel IEF with Pharmalyte 4-6.5 (GE Healthcare) was used with $5 \mu$ g of non-reduced 6C sample and electrophoresis conducted at $2000 \mathrm{~V}, 7 \mathrm{~mA}, 7 \mathrm{~W}$ for $30 \mathrm{~min}$. The gel was fixed with $20 \%$ TFA for $30 \mathrm{~min}$, stained with Coomassie R250 for $30 \mathrm{~min}$, and then detained with $40 \%$ methanol and $10 \%$ acetic acid.

Free thiol determination. Free thiol (number of free cysteine residues) was measured using Ellman's reagent (Thermo Scientific) following manufacturer's instructions. The $6 \mathrm{C}$ protein was concentrated to $1.4 \mathrm{mg} / \mathrm{mL}$ $(\sim 85 \mu \mathrm{M})$ prior to thiol assay. A standard curve was constructed using known concentrations of reduced glutathione. Absorbance was measured at $412 \mathrm{~nm}$.

Disulfide mapping. The $6 \mathrm{C}$ protein was buffer exchanged into $50 \mathrm{mM}$ Tris buffer containing $10 \mathrm{mM} \mathrm{CaCl}_{2}$, $\mathrm{pH} 7$ without denaturation or alkylation. Samples were digested with thermolysin (Promega) at a 1:10 enzyme to protein ratio overnight at $37^{\circ} \mathrm{C}$. A portion of the digest was reduced using $20 \mathrm{mM}$ TECP [Tris (2-carboethyl) phosphine] at $37^{\circ} \mathrm{C}$ for $30 \mathrm{~min}$. The digested peptides were then subjected to LC/MS using a C18 column (2.1 $\times 150 \mathrm{~mm}, 1.7 \mu \mathrm{m}$, Waters $\mathrm{BEH}$ ) set to $40^{\circ} \mathrm{C}$. Mobile phases were A (water $+0.05 \% \mathrm{TFA}$ ) and B (acetonitrile $+0.05 \%$ TFA) and the peptides were eluted using a $1-20 \% \mathrm{~B}$ gradient over $90 \mathrm{~min}$ at $0.2 \mathrm{~mL} / \mathrm{min}$ flowrate. Differences between the reduced and non-reduced samples were used to locate the disulfide peptides. Peptides were identified using a Waters Synapt G2 or QToF Premier mass spectrometer in positive-ion mode and a mass range of 100-3000 Da. The identities of the disulfide peptides observed in the thermolysin digest were confirmed with $\mathrm{MS}^{\mathrm{e}}$ data. Peptides were considered confirmed if at least two a, b or y ions were observed for each individual peptide in the disulfide peptide pair. A control protein, $\mathrm{R} 0.6 \mathrm{C}^{20}$ was used to develop and optimize the mapping method.

\section{Data availability}

The datasets generated during and/or analysed during the current study are available from the corresponding author on reasonable request.

Received: 13 August 2019; Accepted: 30 December 2019;

Published online: 15 January 2020

\section{References}

1. Delves, M. J., Angrisano, F. \& Blagborough, A. M. Antimalarial Transmission-Blocking Interventions: Past, Present, and Future. Trends in parasitology 34, 735-746, https://doi.org/10.1016/j.pt.2018.07.001 (2018).

2. Ishino, T. \& Tsuboi, T. Progress toward a transmission-blocking vaccine against malaria. The Lancet. Infectious diseases 18, 927-928, https://doi.org/10.1016/s1473-3099(18)30358-x (2018).

3. Acquah, F. K., Adjah, J., Williamson, K. C. \& Amoah, L. E. Transmission-blocking vaccines: old friends and new prospects. Infection and immunity, https://doi.org/10.1128/iai.00775-18 (2019).

4. Shimp, R. L. Jr. et al. Development of a Pfs25-EPA malaria transmission blocking vaccine as a chemically conjugated nanoparticle. Vaccine 31, 2954-2962, https://doi.org/10.1016/j.vaccine.2013.04.034 (2013).

5. Talaat, K. R. et al. Safety and Immunogenicity of Pfs25-EPA/Alhydrogel(R), a Transmission Blocking Vaccine against Plasmodium falciparum: An Open Label Study in Malaria Naive Adults. PloS one 11, e0163144, https://doi.org/10.1371/journal.pone.0163144 (2016).

6. Sagara, I. et al. Safety and immunogenicity of Pfs25H-EPA/Alhydrogel, a transmission-blocking vaccine against Plasmodium falciparum: a randomised, double-blind, comparator-controlled, dose-escalation study in healthy Malian adults. The Lancet. Infectious diseases 18, 969-982, https://doi.org/10.1016/s1473-3099(18)30344-x (2018).

7. Acquah, F. K. et al. Antibody responses to two new Lactococcus lactis-produced recombinant Pfs $48 / 45$ and Pfs 230 proteins increase with age in malaria patients living in the Central Region of Ghana. Malaria journal 16, 306, https://doi.org/10.1186/s12936-0171955-0 (2017).

8. Stone, W. J. R. et al. Unravelling the immune signature of Plasmodium falciparum transmission-reducing immunity. Nature communications 9,558 , https://doi.org/10.1038/s41467-017-02646-2 (2018).

9. Lee, S. M. et al. An N-terminal Pfs 230 domain produced in baculovirus as a biological active transmission-blocking vaccine candidate. Clinical and vaccine immunology: CVI 24, e00140, https://doi.org/10.1128/cvi.00140-17 (2017).

10. Lee, S. M. et al. Expression and purification optimization of an N-terminal Pfs 230 transmission-blocking vaccine candidate. Protein expression and purification 160, 56-65, https://doi.org/10.1016/j.pep.2019.04.001 (2019).

11. MacDonald, N. J. et al. Structural and Immunological Characterization of Recombinant 6-Cysteine Domains of the Plasmodium falciparum Sexual Stage Protein Pfs230. The Journal of biological chemistry 291, 19913-19922, https://doi.org/10.1074/jbc. M116.732305 (2016).

12. van Dijk, M. R. et al. A central role for P48/45 in malaria parasite male gamete fertility. Cell 104, 153-164 (2001).

13. Gerloff, D. L., Creasey, A., Maslau, S. \& Carter, R. Structural models for the protein family characterized by gamete surface protein Pfs230 of Plasmodium falciparum. Proceedings of the National Academy of Sciences of the United States of America 102, 13598-13603, https://doi.org/10.1073/pnas.0502378102 (2005).

14. Kocken, C. H. et al. Cloning and expression of the gene coding for the transmission blocking target antigen Pfs $48 / 45$ of Plasmodium falciparum. Molecular and biochemical parasitology 61, 59-68 (1993).

15. Roeffen, W. et al. Plasmodium falciparum: Production and Characterization of Rat Monoclonal Antibodies Specific for the SexualStage Pfs48/45 Antigen. Experimental parasitology 97, 45-49, https://doi.org/10.1006/expr.2000.4586 (2001).

16. Kundu, P. et al. Structural delineation of potent transmission-blocking epitope I on malaria antigen Pfs48/45. Nature communications 9, 4458, https://doi.org/10.1038/s41467-018-06742-9 (2018).

17. Outchkourov, N. et al. Epitope analysis of the malaria surface antigen pfs $48 / 45$ identifies a subdomain that elicits transmission blocking antibodies. The Journal of biological chemistry 282, 17148-17156, https://doi.org/10.1074/jbc.M700948200 (2007).

18. Outchkourov, N. S. et al. Correctly folded Pfs $48 / 45$ protein of Plasmodium falciparum elicits malaria transmission-blocking immunity in mice. Proceedings of the National Academy of Sciences of the United States of America 105, 4301-4305, https://doi. org/10.1073/pnas.0800459105 (2008).

19. Theisen, M., Jore, M. M. \& Sauerwein, R. Towards clinical development of a Pfs48/45-based transmission blocking malaria vaccine. Expert review of vaccines 16, 329-336, https://doi.org/10.1080/14760584.2017.1276833 (2017). 
20. Singh, S. K. et al. Construct design, production, and characterization of Plasmodium falciparum $48 / 45$ R0.6C subunit protein produced in Lactococcus lactis as candidate vaccine. Microbial cell factories 16, 97, https://doi.org/10.1186/s12934-017-0710-0 (2017).

21. Davidson, E. A. \& Gowda, D. C. Glycobiology of Plasmodium falciparum. Biochimie 83, 601-604 (2001).

22. Kapulu, M. C. et al. Comparative assessment of transmission-blocking vaccine candidates against Plasmodium falciparum. Scientific reports 5, 11193, https://doi.org/10.1038/srep11193 (2015)

23. Mamedov, T. et al. A Plant-Produced in vivo deglycosylated full-length Pfs $48 / 45$ as a Transmission-Blocking Vaccine Candidate against malaria. Scientific reports 9, 9868, https://doi.org/10.1038/s41598-019-46375-6 (2019).

24. Lennartz, F. et al. Structural basis for recognition of the malaria vaccine candidate Pfs $48 / 45$ by a transmission blocking antibody. Nature communications 9, 3822, https://doi.org/10.1038/s41467-018-06340-9 (2018).

25. Lee, S. M. et al. Assessment of Pfs 25 expressed from multiple soluble expression platforms for use as transmission-blocking vaccine candidates. Malaria journal 15, 405, https://doi.org/10.1186/s12936-016-1464-6 (2016).

26. Lee, S. M., Plieskatt, J. L. \& King, C. R. Peptide data on the disulfide bond analysis of baculovirus produced Pfs 25 by LC-MSMS. Data Brief 18, 209-233, https://doi.org/10.1016/j.dib.2018.03.034 (2018).

27. Lee, S. M., Plieskatt, J. \& King, C. R. Disulfide bond mapping of Pfs25, a recombinant malaria transmission blocking vaccine candidate. Analytical biochemistry 542, 20-23, https://doi.org/10.1016/j.ab.2017.11.009 (2018).

28. Fung, K. L. et al. Using the BacMam Baculovirus System to Study Expression and Function of Recombinant Efflux Drug Transporters in Polarized Epithelial Cell Monolayers. Drug metabolism and disposition: the biological fate of chemicals 44, 180-188, https://doi. org/10.1124/dmd.115.066506 (2016).

29. Luo, L., Nishi, K., MacLeod, E. \& Sabara, M. I. Expression and Characterization of HA1 Protein of Highly Pathogenic H5N1 Avian Influenza Virus for Use in a Serodiagnostic Assay. Transboundary and emerging diseases 64, 432-441, https://doi.org/10.1111/ tbed.12382 (2017).

30. Tonkin, M. L. et al. Structural and biochemical characterization of Plasmodium falciparum 12 (Pf12) reveals a unique interdomain organization and the potential for an antiparallel arrangement with Pf41. The Journal of biological chemistry 288, 12805-12817, https://doi.org/10.1074/jbc.M113.455667 (2013).

31. Hegde, R. S. \& Kang, S. W. The concept of translocational regulation. The Journal of cell biology 182, 225-232, https://doi. org/10.1083/jcb.200804157 (2008).

32. Klaus, T. et al. Overcoming inefficient secretion of recombinant VEGF-C in baculovirus expression vector system by simple purification of the protein from cell lysate. Protein expression and purification 110, 151-158, https://doi.org/10.1016/j. pep.2015.03.001 (2015).

33. Matsubara, H., Singer, A. \& Sasaki, R. M. Effect of proline residue on the hydrolysis of substrates by thermolysin. Biochemical and biophysical research communications 34, 719-724 (1969).

34. Miura, K. et al. Qualification of standard membrane-feeding assay with Plasmodium falciparum malaria and potential improvements for future assays. PloS one 8, e57909, https://doi.org/10.1371/journal.pone.0057909 (2013).

35. Miura, K. et al. Development and characterization of a standardized ELISA including a reference serum on each plate to detect antibodies induced by experimental malaria vaccines. Vaccine 26, 193-200, https://doi.org/10.1016/j.vaccine.2007.10.064 (2008).

36. Miura, K. et al. Transmission-blocking activity is determined by transmission-reducing activity and number of control oocysts in Plasmodium falciparum standard membrane-feeding assay. Vaccine 34, 4145-4151, https://doi.org/10.1016/j.vaccine.2016.06.066 (2016).

\section{Acknowledgements}

The authors thank Ashley Birkett for his support and assistance in conceptualization of the work presented here and in the review of this manuscript. In addition, the authors thank several contributors to the analyses presented here. Yimin Wu for scientific review of the manuscript. Bingbing Deng and Carole Long for mouse immunization and ex vivo studies. Luwen Zhou, Thao P. Pham and Ababacar Diouf for SMFA support. David McAdams for performing SDS-PAGE and Western on the purified proteins. Robert Sauerwein for providing the 85RF45.1 monoclonal antibody. PPD Laboratories for performing disulfide mapping. Lastly, the authors thank the project team at Syngene International, a Biocon company, in Bangalore, India for the cloning, production, and preliminary analysis of the recombinant Pfs $48 / 45$ proteins described here. The work presented here was funded by a grant from the Bill \& Melinda Gates Foundation. The views expressed herein are solely those of the authors and do not necessarily reflect the views of the Foundation. The mouse immunization and SMFA activities were supported in part by the Intramural Research Program of NIAID, N.I.H.

\section{Author contributions}

S.M.L. conceived study design, oversaw protein projects/analysis, and manuscript preparation. J.M.H. conducted the biochemical analysis of the protein and assisted in manuscript review. K.M. conducted animal immunization study including ELISAs and SMFA. S.B.J. and D.B.V. designed and provided oversight of the biochemical analysis and reviewed the manuscript. C.R.K. provided oversight for the overall study effort and in writing and reviewing the manuscript. J.L.P. led the overall study effort, data analysis, and manuscript preparation. All authors read and approved the final manuscript.

\section{Competing interests}

The authors declare no competing interests.

\section{Additional information}

Supplementary information is available for this paper at https://doi.org/10.1038/s41598-019-57384-w.

Correspondence and requests for materials should be addressed to S.-M.L.

Reprints and permissions information is available at www.nature.com/reprints.

Publisher's note Springer Nature remains neutral with regard to jurisdictional claims in published maps and institutional affiliations. 
(c) (i) Open Access This article is licensed under a Creative Commons Attribution 4.0 International License, which permits use, sharing, adaptation, distribution and reproduction in any medium or format, as long as you give appropriate credit to the original author(s) and the source, provide a link to the Creative Commons license, and indicate if changes were made. The images or other third party material in this article are included in the article's Creative Commons license, unless indicated otherwise in a credit line to the material. If material is not included in the article's Creative Commons license and your intended use is not permitted by statutory regulation or exceeds the permitted use, you will need to obtain permission directly from the copyright holder. To view a copy of this license, visit http://creativecommons.org/licenses/by/4.0/.

(C) The Author(s) 2020 